\title{
Drivers of carbon variations in the
}

\section{Eocene}

ELENI ANAGNOSTOU ${ }^{1}$, DONALD PENMAN ${ }^{2}$, THOMAS WESTERHOLD $^{3}$, TALI LEA BABILA ${ }^{4}$ AND GUILLAUME FONTORBE $^{1}$

${ }^{1}$ GEOMAR Helmholtz Centre for Ocean Research Kiel

${ }^{2}$ Utah State University

${ }^{3}$ University of Bremen

${ }^{4}$ University of Southampton

Presenting Author: eanagnostou@geomar.de

Reconstructions of atmospheric and oceanic chemistry in the Eocene (56-34 Ma) has been a great challenge in the paleoclimate community, because of the paucity of wellpreserved sedimentary archives with well-tuned age models, and the limited availability of refined geochemical tracers. Here, we summarize our recent compilations of seawater $\mathrm{pH}$ and derived atmospheric carbon dioxide concentrations $\left(\mathrm{CO}_{2}\right)$ from planktonic foraminiferal $\delta^{11} \mathrm{~B}$ [1], alongside other marine-derived $\mathrm{CO}_{2}$ records and recent benthic foraminiferal $\delta^{13} \mathrm{C}$ and $\delta^{18} \mathrm{O}$ compilations [2]. We then explore their relationship to variations in weathering, volcanism, ocean circulation, organic carbon burial and recent box model calculations, to identify the key mechanisms driving changes in $\mathrm{CO}_{2}$ and climate (i.e. temperature) through the Eocene.

[1] Anagnostou, et al., (2020), Nature Comm 11, 1-9.

[2] Westerhold, et al., (2020), Science 369, 1383-1387. 